Article

\title{
Expression Levels of Inflammatory and Oxidative Stress-Related Genes in Skin Biopsies and Their Association with Pityriasis Alba
}

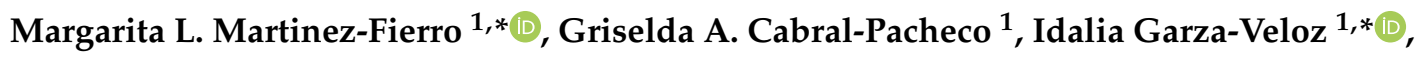 \\ Andrés E. Campuzano-García ${ }^{2}$, Alma P. Díaz-Alonso ${ }^{1,2}$, Virginia Flores-Morales ${ }^{3}{ }^{(0)}$, \\ Iram P. Rodriguez-Sanchez ${ }^{4}$ (D) , Ivan Delgado-Enciso ${ }^{5}$ (D) and Jorge Rios-Jasso ${ }^{1}$ \\ 1 Molecular Medicine Laboratory, Doctorado en Ciencias con Orientación en Medicina Molecular, Unidad \\ Académica de Medicina Humana y C.S., Universidad Autónoma de Zacatecas, Zacatecas 98160, Mexico; \\ gris_elda_ai91@hotmail.com (G.A.C.-P.); patriciaalonsodd@gmail.com (A.P.D.-A.); \\ nietzx72@gmail.com (J.R.-J.) \\ 2 Hospital General Zacatecas “Luz González Cosío”, Servicios de Salud de Zacatecas, Zacatecas 98160, Mexico; \\ campuzano3@hotmail.com \\ 3 Laboratorio de Síntesis Asimétrica y Bioenergética (LSAyB), Doctorado en Ciencias con Orientación en \\ Medicina Molecular, Unidad Académica de Medicina Humana y C.S., Universidad Autónoma de Zacatecas, \\ Zacatecas 98160, Mexico; virginia.flores@uaz.edu.mx \\ 4 Laboratorio de Fisiología Molecular y Estructural, Facultad de Ciencias Biológicas, Universidad Autónoma \\ de Nuevo León, Monterrey 66455, Mexico; iramrodriguez@gmail.com \\ 5 School of Medicine, University of Colima, and Cancerology State Institute, Colima State Health Services, \\ Colima 28040, Mexico; ivan_delgado_enciso@ucol.mx \\ * Correspondence: margaritamf@uaz.edu.mx (M.L.M.-F.); idaliagv@uaz.edu.mx (I.G.-V.); \\ Tel.: +52-(492)-9256690 (ext. 4511) (M.L.M.-F.); +52-(492)-9256690 (ext. 4510) (I.G.-V.)
}

Received: 25 May 2020; Accepted: 2 July 2020; Published: 17 July 2020

\begin{abstract}
Background and objectives: Pytiriasis alba (PA) is a common skin disorder which affects $80 \%$ of children between six and 16 years. The etiology of PA is unclear, but hypo-pigmented patches in photo-exposed zones characterize the disease. Because the high ultraviolet exposition of the skin promotes an acute inflammatory response and an increase of oxidative stress (OS), this study aimed to evaluate the expression levels of inflammatory and OS-related genes in skin biopsies, and their association with PA. Materials and Methods: A cross-sectional study was carried out. Skin biopsies of the lesion sites and healthy skin (controls) from 16 children with PA were evaluated. The tissue expression of IL-4, IL-6, IL-17A, TNF $\alpha$, INF $\gamma$, IL-1 $\beta$, SOD1, and HMOX1 was analyzed by qRT-PCR, using SYBR Green and glyceraldehyde-3-phosphate dehydrogenase gene as the endogenous control. Results: There were differences in the $\triangle \mathrm{Cq}$ values of HMOX1, SOD1, IL-6, and IFN $\gamma$ between tissue with lesions and healthy skin $(p<0.05)$. Compared with healthy skin, IL-6, IFN $\gamma$, HMOX1, and SOD1 were predominantly under-expressed in the lesion sites. However, $25 \%$ of skin biopsies with lesions showed over-expression of these four genes. Positive correlations between the expression of IL-6 and HMOX1, SOD1, and IFN $\gamma(p<0.05)$ were also observed. Conclusions: Our results suggest the presence of molecular stages of PA, defined according to the over-expression (first stage) or under-expression (second stage) of the HMOX1, SOD1, IL-6, and IFN $\gamma$ genes in abnormal skin tissue. These findings may have implications for the selection of treatment for PA-related lesions.
\end{abstract}

Keywords: Pityriasis Alba; gene expression; oxidative stress; inflammatory stress 


\section{Introduction}

Pityriasis alba (PA) is a self-limited benign skin disease that occurs most frequently in childhood [1]. PA commonly occurs in patients between 6 and 16 years of age, and affects $80 \%$ of children living in rural areas of developing countries [2,3]. Risk factors of PA are closely associated with those of atopic dermatitis, and include exposure to sunlight, low socioeconomic strata, nutritional deficiencies, and iron deficiency anemia, among others [4]. Furthermore, PA appears earlier in patients with skin phototype IV and V [2].

Clinically, PA is characterized by hypochromic scaly macules that appear more frequently in areas of skin exposed to sunlight [5]. Macules are oval with defined edges, and are up to $4 \mathrm{~cm}$ in diameter. Likewise, hypopigmented lesions of PA can recur [2]. Usually, two to three hypochromic lesions occur on the cheeks, around the mouth, around the eyes, and on the front and back of the forearms, but the rest of the skin on the body is not exempt [6]. In adults, the characteristic macules of PA may occur on the lower portion of the body trunk in a disseminated form. Histological studies have shown hyperkeratosis, spongiosis, acanthosis, and lymphocytic infiltration [7]. Three stages of the disease have been described. The early-stage characterized by well-delimited macules less than $2 \mathrm{~cm}$ in diameter, with erythema and follicular papules with points. In the intermediate stage the lesions increase in size up to $5 \mathrm{~cm}$, and there is desquamatory hypopigmentation with tiny pointy papules compared to the previous stage. Finally, in the late stage, there are patches of $2-5 \mathrm{~cm}$ in diameter, hypopigmented, with irregular edges, with fine desquamation and without follicular papules [6]. In addition, rare variants have been described in adults, where the lesions are hyperchromic and diffuse [2].

The etiology of PA is unknown and there are currently few studies focused on this condition. The most acceptable explanation for the physiopathology of PA proposes an insult in the epidermis caused by ultraviolet (UV) irradiation [8]. Inflammatory cytokines, produced by keratinocytes or other immune cells, are increased after UV exposition and are closely related to changes in pigmentation in other skin disorders [8-10]. These molecules include interleukin-18 (IL-18) and interferon gamma (IFN- $\gamma$ ), among others [11-14]. Accordingly, and because the type IV hypersensitivity mechanism that causes post-inflammatory skin depigmentation has been previously suggested to occur in PA [2], in this study, the levels of inflammatory $(I L-4, I L-6, I L-1 \beta, I L-17 A$, tumor necrosis factor-alpha, and INF $\gamma$ ) and oxidative stress-related genes (superoxide dismutase 1 and heme oxygenase 1) were quantified in skin biopsies, and their association with PA was evaluated.

\section{Materials and Methods}

\subsection{Study Population}

We performed a cross-sectional study in Zacatecas, Mexico. It was conducted according to the guidelines laid down in the Declaration of Helsinki, and the protocol was approved by the Ethics Committee of the General Hospital “Luz Gonzalez Cosío” (Approval ID: 02020/2019, Date: 8 July 2019). The participants were recruited in the Dermatology service of General Hospital "Luz González Cosío" from the pediatric population referred for medical consultation for possible PA. The confirmation of the study population was done as follows: (1) Detailed information related to the protocol was provided to each participant, and his/her parent or guardian, and written informed consent and assent were obtained. All the participants who provided signed informed consent/assent underwent a physical examination and completed a questionnaire about the risk factors for PA. (2) Then, children with PA were identified for the study according to the guidelines of The British Association of Dermatologists and previous reports of PA differential diagnosis $[15,16]$. The study exclusion criteria involved the existence of other conditions, such as other hypopigmentation-related diseases, vitiligo, pityriasis veriscolor, treatment with steroids and/or photoprotection in the last three months, recent strong sun exposure such as outside sport activities, previous diagnosis of atopic dermatitis, and/or positive test by Wood lamp for other pathologies. Accordingly, 16 patients were included in the final study. 


\subsection{Biological Samples and Clinical Data}

Two $3 \mathrm{~mm}$ punch biopsies, $10 \mathrm{~mm}$ apart, were taken from the lesion (child's face) under local anesthesia. Each participant also donated a healthy skin biopsy (control) from the arm area, located in its internal region where there was no sun exposure. Tissue biopsies were preserved in RNA later solution (Life Technologies, Carlsbad, CA, USA) and stored at $-80{ }^{\circ} \mathrm{C}$ until use. Additional clinical and laboratory data were obtained from the clinical records.

\subsection{RNA Isolation and $c D N A$ Synthesis}

Total RNA was isolated from the skin biopsies using mechanical homogenization, using a Qiagen RNeasy ${ }^{\circledR}$ Mini Kit (Qiagen, West Sussex, UK) according to the manufacturer's protocol. The RNA concentration and its quality were determined by measurement of the optical density at $260 \mathrm{~nm}$ and the ratio 260/280, respectively, using a NanoDrop 2000 Spectrophotometer (Thermo Fisher Scientific, Wilmington, DE, USA). Complementary DNA (cDNA) was synthesized from $1.0 \mu \mathrm{g}$ of total RNA in a final volume of $20 \mu \mathrm{L}$, using a High Capacity cDNA Reverse Transcription Kit (Thermo Fisher Scientific, Wilmington, DE, USA) and random hexamers, according to the manufacturer's instructions. The final cDNA concentration was measured, and the samples were stored at $-20{ }^{\circ} \mathrm{C}$ until use.

\subsection{Gene Selection and Primer Design}

Eight genes representing inflammatory signaling pathways and oxidative stress-related genes were selected for this study, including Interleukin (IL) 4 (IL-4), IL-6, IL-17A, IL-1 $\beta$, Tumor necrosis factor-alpha $(T N F \alpha)$, interferon gamma $(I N F \gamma)$, superoxide dismutase 1 (SOD1), and heme oxygenase 1 (HMOX1). The glyceraldehyde-3-phosphate dehydrogenase (GAPDH) gene was selected as the internal control. Gene-specific primers for quantitative real-time polymerase chain reaction (qRT-PCR) assay were designed, and provided by T4OLIGO ${ }^{\circledR}$ (T4OLIGO, Irapuato, GTO, Mexico). Sequences of forward and reverse primers and product sizes for all the evaluated genes are listed in Table 1.

Table 1. General information of the oligonucleotides used in the study for the qRT-PCR assays.

\begin{tabular}{cclcc}
\hline Gene Symbol & GenBank Number & \multicolumn{1}{c}{ Primer Sequence $\left(\mathbf{5}^{\prime}\right.$ - $\left.\mathbf{3}^{\prime}\right)$} & Tm $\left({ }^{\circ} \mathbf{C}\right)$ & Product Size (bp) \\
\hline IL-4 & NM_000589 & $\begin{array}{l}\text { F: GACATCTTTGCTGCCTCCAA } \\
\text { R: GTGCGACTGCACAGCAGTT }\end{array}$ & 60 & 128 \\
\hline IL-6 & NM_000600 & $\begin{array}{l}\text { F: CCCTGAGAAAGGAGACATGT } \\
\text { R: TGAAAAAGATGGATGCTTCCAA }\end{array}$ & 60 & 111 \\
\hline IL-17A & NM_002190 & $\begin{array}{l}\text { F: TGGAATCTCCACCGCAATGA } \\
\text { R: GTGGACTACCACATGAACTC }\end{array}$ & 60 & 116 \\
\hline TNF- $\alpha$ & NM_000594 & $\begin{array}{l}\text { F: CAGGCAGTCAGATCATCTTC } \\
\text { R: CCAATGCCCTCCTGGCCA }\end{array}$ & 60 & 121 \\
\hline IFN- $\gamma$ & NM_000619 & $\begin{array}{l}\text { F: AGGAAGACATGAATGTCAAGTT } \\
\text { R: GAATGTCCAACGCAAAGCAAT }\end{array}$ & 60 & 108 \\
\hline IL-1 $\beta$ & NM_000576 & $\begin{array}{l}\text { F: GGAGCAACAAGTGGTGTTCT } \\
\text { R: ACCTGTCCTGCGTGTTGAAA }\end{array}$ & 60 & 116 \\
\hline SOD1 & NM_000454 & $\begin{array}{l}\text { F: GAGGCATGTTGGAGACTTGG } \\
\text { R: ACAAGCCAAACGACTTCCAG }\end{array}$ & 60.5 & 205 \\
\hline HMOX1 & NM_002133 & $\begin{array}{l}\text { F: GCTCAACATCCAGCTCTTTGA } \\
\text { R: TGTAAGGACCCATCGGAGAA }\end{array}$ & 60.5 & 196 \\
\hline GAPDH & NM_002046 & F: GAGTCAACGGATTTGGTCGT & 60.1 & 214 \\
\hline
\end{tabular}

\subsection{Quantitative Real-Time Polymerase Chain Reaction}

All the qRT- PCR experiments were conducted using a StepOne Plus Real-Time PCR System (Applied Biosystems, Foster City, CA, USA) in 96-well PCR plates. Each qRT-PCR reaction was performed in a $20 \mu \mathrm{L}$ reaction mix containing $15 \mathrm{ng}$ of template cDNA, 1X SYBR Green PCR Master 
Mix (Applied Biosystems, Foster City, CA, USA), and $500 \mathrm{nM}$ of each primer. All samples were analyzed in duplicate, and each experiment included two non-template controls to detect any template contamination. Melting curve analysis was done to confirm the specificity of amplification and the lack of primer dimers. The thermal cycle program consisted of an initial denaturation at $95^{\circ} \mathrm{C}$ for $10 \mathrm{~min}$, followed by an amplification step for 40 cycles of $15 \mathrm{~s}$ at $95^{\circ} \mathrm{C}$ and $1 \mathrm{~min}$ at $60^{\circ} \mathrm{C}$. The results were obtained using the $2^{-\Delta \Delta \mathrm{Cq}}$ method [17], and delta $\mathrm{Cq}(\Delta \mathrm{Cq})$ values obtained for the different genes were compared using GAPDH as a reference.

\subsection{Statistical Analysis}

Categorical variables were described as frequency and percentages, and continuous variables were described using mean and median values. The normality of data distribution was evaluated using the Kolmogorov-Smirnov test. Simple comparisons of $\Delta \mathrm{Cq}$ values and/or relative expression levels between skin with lesions and healthy skin (control) were determined by Student's $t$-test when the data were normally distributed; otherwise, the Mann-Whitney test was used. Pearson's correlation analysis was done to determine whether there were correlations between the expression tissue levels of the genes of interest and clinical variables. Statistical analysis was carried out with the Sigma Plot version 12.0-statistic software package (Systat Software Inc., San Jose, CA, USA). $p$-values $<0.05$ were considered significant.

\section{Results}

The study group included 16 patients between 6-11 years of age. Table 2 shows the general characteristics of the study population. Seventy-five percent of the cases were male, and the remaining $25 \%$ were female. The average weight and body mass index (BMI) was $32.3 \mathrm{~kg}( \pm 11.8)$ and $20 \mathrm{~kg} / \mathrm{m}^{2}$ $( \pm 4.5)$, respectively. Abnormal hemoglobin levels and/or white blood cell counts were not observed. The average time of sun exposure was $6.3 \mathrm{~h}$ a day.

Table 2. General characteristics of the study population.

\begin{tabular}{cc}
\hline Variable & Patients $(\mathbf{n}=\mathbf{1 6})$ \\
\hline Gender & \\
Male, $\mathrm{n}(\%)$ & $12(75)$ \\
Female, $\mathrm{n}(\%)$ & $4(25)$ \\
Age $($ years $)$ & $8.9 \pm 3.1$ \\
Weight $(\mathrm{kg})$ & $32.3 \pm 11.8$ \\
Height $(\mathrm{cm})$ & $125.4 \pm 14.3$ \\
Body mass index $\left(\mathrm{kg} / \mathrm{m}^{2}\right)$ & $20.0 \pm 4.5$ \\
Hemoglobin $(\mathrm{mg} / \mathrm{dL})$ & $13.4 \pm 1.5$ \\
Leucocytes $\left(10^{3} / \mu \mathrm{L}\right)$ & $7.3 \pm 2.5$ \\
Lymphocytes $\left(10^{3} / \mu \mathrm{L}\right)$ & $3103.8 \pm 1932.3$ \\
Neutrophils $\left(10^{3} / \mu \mathrm{L}\right)$ & $3674.4 \pm 2406.5$ \\
Creatinine $(\mathrm{mg} / \mathrm{dL})$ & $0.41 \pm 0.10$ \\
Sun exposure $(\mathrm{h} / \mathrm{day})$ & $6.31 \pm 1.44$ \\
\hline
\end{tabular}

Data are presented as the frequency and percentage, or as the mean \pm standard deviation.

The panel of eight genes related to oxidative stress and the inflammatory response was evaluated in 32 skin biopsies from 16 patients. Sixteen of these biopsies were from the lesion area, and 16 were from healthy skin. Figure 1 shows the results of the analysis of $\Delta \mathrm{Cq}$ values of the genes of interest in lesions and healthy areas from children with PA. 


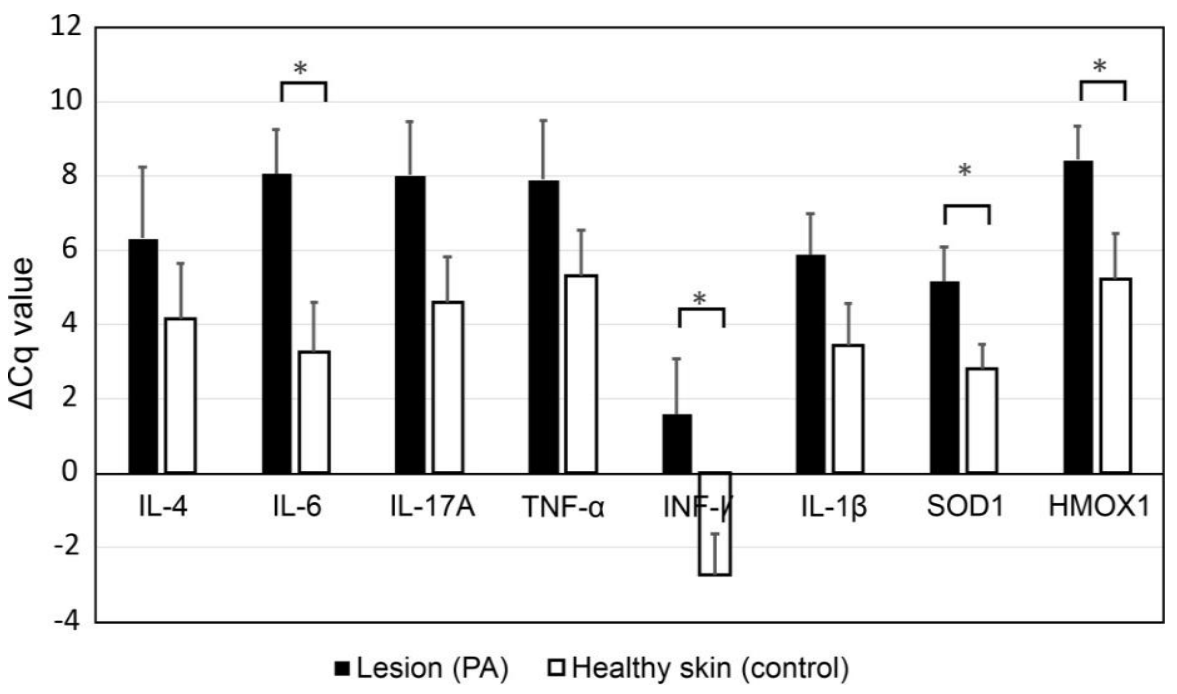

Figure 1. Analysis of delta $\mathrm{Cq}(\triangle \mathrm{Cq})$ values of the genes of interest in skin with and without lesions from children with Pytiriasis Alba. $\triangle \mathrm{Cq}$ values were obtained for genes of interest using GAPDH as the internal control. The obtained values were compared between skin with and without lesions (control) from the same children. Data are represented as the mean $\pm \mathrm{SE}$ of $\Delta \mathrm{Cq}$ values from 16 participants (see Materials and Methods section for details). Significant $p$-values $(p<0.05)$ are highlighted with an asterisk.

There were differences in $\Delta$ Cq values for IL-6 $(p=0.012)$, INF $\gamma(p=0.02)$, SOD1 $(p=0.036)$, and HMOX1 $(p=0.042)$ between tissue with lesions and healthy skin $(p<0.05)$. Differences in $\Delta \mathrm{Cq}$ values of IL-4, IL-17A, TNF $\alpha$, and IL- $1 \beta$ between damaged skin and control skin were not identified. Compared to healthy skin, skin with lesions showed under-expression of IL-6, INF $\gamma$, SOD1, and HMOX1, respectively (Figure 2). The range of expression for the significant genes was from -1.86 to -0.403 for IL-6, -2.34 to 1.12 for INF $\gamma,-3.95$ to -0.602 for SOD1, and -2.59 to 0.59 for HMOX1, respectively (See Figure 2).



Figure 2. Expression levels of the genes of interest in injured skin from children with Pytiriasis Alba. Delta $\mathrm{Cq}(\Delta \mathrm{Cq})$ values of the genes of interest were used to calculate the relative expression level for each gene of interest by the $2^{-\Delta \Delta \mathrm{Cq}}$ method, using the healthy skin data from each participant (control) as a calibrator. The mean of Log 2 of the expression level \pm SE (see Materials and Methods section for details) is shown.

Twenty-five per cent of skin biopsies with lesions showed over-expression of IL-6, INF $\gamma$, SOD1, and HMOX1, respectively (Supplementary Figure S1). 
Table 3 displays the results of the correlation analysis of the expression levels for the genes of interest and the clinical variables. There was a positive correlation between HMOX1 expression and weight $\left(p=3.8 \times 10^{-3}\right.$, correlation coefficient: 0.718$)$, height ( $p=8.3 \times 10^{-3}$, correlation coefficient: $0.673)$ and $\mathrm{BMI}\left(p=3.5 \times 10^{-2}\right.$, correlation coefficient: 0.565$)$. Strong positive correlations between the expression of IL-6 and IL-17, INF $\gamma$, IL-1B, SOD1, and HMOX1 were also observed $(p<0.05)$.

Table 3. Correlation test between genes and clinical variables.

\begin{tabular}{|c|c|c|c|}
\hline Variable 1 & Variable 2 & Correlation Coefficient & $p$-Value \\
\hline IL-4 & HMOX1 & 0.611 & $3.5 \times 10^{-2}$ \\
\hline \multirow{5}{*}{ IL-6 } & IL-17 & 0.924 & $3.1 \times 10^{-7}$ \\
\hline & INF- $\gamma$ & 0.955 & $9.3 \times 10^{-9}$ \\
\hline & IL-1B & 0.915 & $6.8 \times 10^{-7}$ \\
\hline & SOD1 & 0.944 & $4.2 \times 10^{-8}$ \\
\hline & HMOX1 & 0.564 & $3.6 \times 10^{-2}$ \\
\hline \multirow{3}{*}{ IL-17 } & INF- $\gamma$ & 0.936 & $9.6 \times 10^{-8}$ \\
\hline & IL-1B & 0.953 & $1.2 \times 10^{-8}$ \\
\hline & SOD1 & 0.892 & $3.5 \times 10^{-6}$ \\
\hline TNF- $\alpha$ & HMOX1 & 0.769 & $1.3 \times 10^{-3}$ \\
\hline \multirow{3}{*}{ INF- $\gamma$} & IL-1B & 0.854 & $2.5 \times 10^{-5}$ \\
\hline & SOD1 & 0.922 & $3.8 \times 10^{-7}$ \\
\hline & HMOX1 & 0.549 & $4.2 \times 10^{-2}$ \\
\hline IL-1B & SOD1 & 0.857 & $2.3 \times 10^{-5}$ \\
\hline SOD1 & HMOX1 & 0.567 & $3.5 \times 10^{-2}$ \\
\hline \multirow{3}{*}{ HMOX1 } & Weight & 0.718 & $3.8 \times 10^{-3}$ \\
\hline & Height & 0.673 & $8.3 \times 10^{-3}$ \\
\hline & Body mass index & 0.565 & $3.5 \times 10^{-2}$ \\
\hline
\end{tabular}

\section{Discussion}

PA is a benign and self-limited dermatological condition that is characterized by the appearance of hypopigmented macules with undefined edges in photo-exposed sites [5]. The stratified architecture of the skin, and its antioxidant systems and melanogenesis capacity, are the major defense mechanisms against ultraviolet radiation (UVr) [18]. Considering that UV exposition of the skin promotes an acute inflammatory response and an increase of OS in other skin diseases $[8,9,14,19,20]$, we evaluated the expression levels of inflammatory and OS-related genes in skin biopsies and their association with PA. Our results showed differences in the $\triangle \mathrm{Cq}$ values of pro-inflammatory cytokine genes (IL-6 and INF $\gamma$ ) and antioxidant-related genes (SOD1 and HMOX1) between skin biopsies with and without lesions. Compared with healthy skin, the expression levels of these genes were predominantly downregulated in lesions. Currently, there are no studies that have evaluated the expression of cytokines and/or OS-related genes in PA. However, in order to explain our results, in Figure 3, our actual knowledge regarding the skin response to exogenous and/or endogenous sources of cell damage was summarized, and our results were also integrated as follows: in normal conditions, when UV light radiates the entire skin layer, it causes photodamage and induces melanogenesis [21] (Figure 3A). Similar to UVr, endogenous sources of skin damage, such as inflammation, induce the production of pro-inflammatory cytokines and generate ROS and RNS [11,12,21]. Melanogenesis, in turn, generates ROS and RNS, and induces pigmentation of the epidermis [22,23]. The pro-inflammatory cytokines may induce the production of collagen, while antioxidant systems combat OS, restoring the cell equilibrium $[13,21,24]$. When UVr falls on dysfunctional or immature skin, or irradiates chronically (Figure 3B), it produces photodamage and initiates the depletion of type I antioxidant systems. Photodamage induces ROS and RNS, as well as pro-inflammatory cytokines-mainly IL-6 and INF- $\gamma$. ROS and RNS induce lipid peroxidation, and 
this process, in turn, increases the oxidative/nitrosative stress state, causing several cell alterations, including protein oxidation, damage to the cell membrane and DNA, alterations in transport, and consequently, apoptosis. It has been reported that high concentrations of hydrogen peroxide and $\mathrm{NO}$ may also inhibit type II antioxidant systems $[13,23,24]$. Therefore, both pro-inflammatory cytokines and ROS/NOS production generate a persistent OS environment [18]. During the acute process, activation of Th1 lymphocytes and/or production of large amounts of INF $\gamma$ by keratinocytes may activate macrophages [12,18]. Macrophages release ROS, NO, and pro-inflammatory cytokines, promoting leukocyte extravasation $[2,12,25]$. This process is in agreement with the perivascular lymphocytic infiltrates occasionally seen in the dermis of patients with PA [7], and it may also explain the observed over-expression of pro-inflammatory cytokines (INF- $\gamma$ and IL-6) and OS-related genes (SOD1 and HMOX1) in the lesions in $25 \%$ of the participants in our study. When IFN $\gamma$ is present, it stimulates CD4 and CD8 cells, which lyse various cell types, such as keratinocytes [11,12], and triggers the expression of NADPH oxidases (NOX4, and NOX1), with concomitant elevation of ROS during the acute inflammatory processes. The expression of IFN $\gamma$ may produce a hypopigmentation phenotype and stop the maturation of the melanosome in stages I and II, when it still has no pigment $[11,13,26]$. Over time, UVr depletes cell antioxidants and reduces the efficiency of the skin's antioxidant systems (Figure 3C) [26]. It has been reported that OS causes failures in the regulation of melanocyte inducing transcription factor (MITF), which sensitizes melanocytes to OS and leads to their death [11,27]. Furthermore, the recurrent inflammatory environment causes epidermal cells to enter a hypermetabolic state [28]. Likewise, the excessive production of metabolites and oxidizing agents of melanocyte leads to autolysis [3]. These facts may explain in part the presence of hyperkeratosis, observed in histological studies [7].

Physiological mediators that reinstate basal pigmentation are difficult to deduce because of their transient expression [18]. However, repigmentation of the lesions likely occurs with the suppression of immune mediators, such as INF- $\gamma$, and cytokines, such as IL-6, IL-4, and TNF- $\alpha$, which are also known to downregulate melanogenesis in melanocytes [18] (Figure 3D). This hypothesis is supported by our results, in which the expression of these mediators was positive and strongly correlated. Likewise, the participation of alpha-melanocyte-stimulating hormone ( $\alpha-\mathrm{MSH})$ in the establishment of the normal redox state and cell homeostasis is supported, because it may increase the expression, synthesis de novo, and activation of tyrosinase (a mediator of melanin production) $[12,29,30]$. Therefore, $\alpha$-MSH stimulates the dendricity of melanocytes, and protects them from superoxide radicals. The production of new melanin can repair the damage caused by ROS in apoptotic tissue [9,18,31,32]. These changes may have an effect on the restoration of the permeability barrier, which is significantly impaired in PA [33].

In spite of the fact that additional studies must be completed to reproduce our results, we consider that the PA phase is critical for the selection of treatment, which may be focused on anti-inflammatory medication as the first step and then on topical antioxidants that can lead to the repigmentation of damaged areas $[8,25,34]$. Because recurrent exposure to UVr can prolong hypochromia for over 10 years, the prevention of UVr exposition is indicated to decrease how long a patient has lesions $[4,5,8,24]$, and to avoid their recurrence.

Finally, some study limitations must be highlighted. For instance, the number of participants included in the study was small, and therefore additional studies must be completed to reproduce our results. In the same sense, due to the small number of subjects, with significant genes differentially expressed, additional statistical comparisons, such as over/under-expression and features of lesions, could not be carried out. These important issues should be considered in future experimental approaches to the study of the molecular pathophysiology of PA. 
A.

Endo/exogenous sources

(Uvr, inflammation)

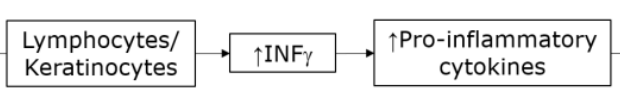

$\uparrow I L-18 \rightarrow \uparrow$ Melanogenesis

Antioxidant defenses:

nonenzymatic/enzymatic

Keratinocytes
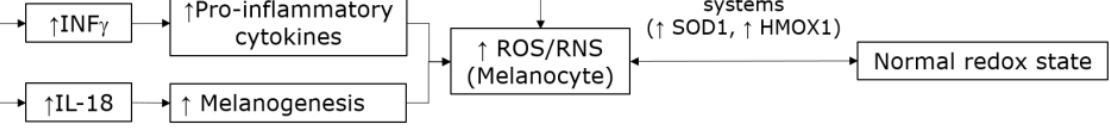

B.

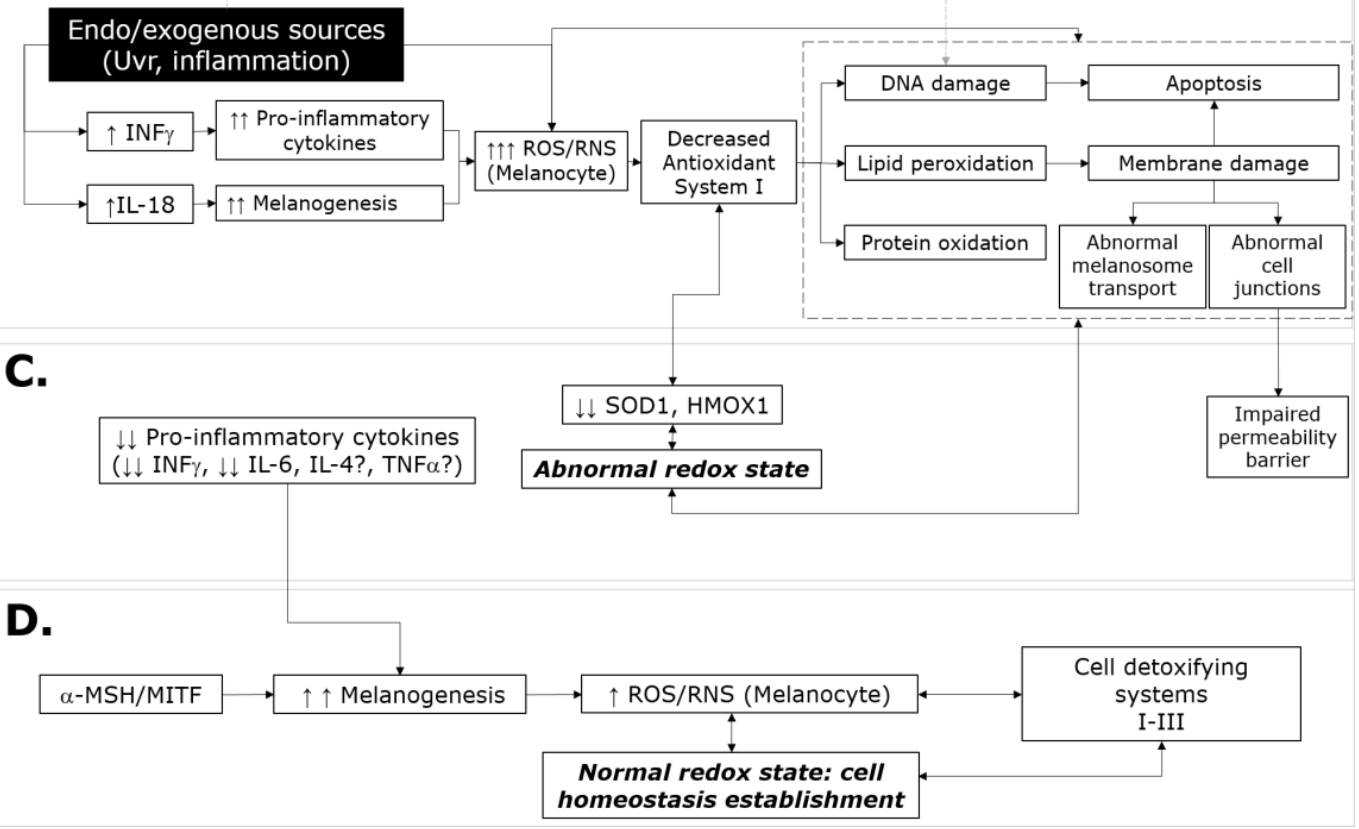

Figure 3. Representation response of skin to ultraviolet radiation (UVr) or other endogenous or exogenous sources of cell damage. In normal conditions (A), when UV light radiates the entire skin layer, it causes photodamage and induces melanogenesis [21]. Other endogenous sources of skin damage, like inflammation, induce the production of pro-inflammatory cytokines and generate ROS and RNS [11,12,21]. Melanogenesis generates ROS and RNS, inhibits pro-inflammatory cytokines, and induces pigmentation of the epidermis [22,23]. The pro-inflammatory cytokines induce the production of collagen, while the antioxidant systems combat OS, restoring the cell equilibrium $[13,21,24]$. When UVr falls on dysfunctional or immature skin (B) or occurs chronically, the skin is photodamaged, and type I antioxidant systems gradually weaken. Skin damage generates ROS and RNS, as well as pro-inflammatory cytokines-mainly IL-6 and INF- $\gamma$. ROS and RNS induce lipid peroxidation, and this process, in turn, increases the oxidative/nitrosative stress state, causing apoptosis, affecting melanogenesis and the transport of melanosomes. These events may produce hypopigmentation, hyperkeratosis, and leucocyte infiltrations [34-36]. Gradually (C), the UVr depletes cell antioxidants and reduces the efficiency of the skin's antioxidant systems [26]. OS causes failures in the regulation of melanocyte-inducing transcription factor (MITF), sensitizing the melanocytes to OS, which leads to cell death $[11,27]$ (D). Physiological basal pigmentation may occur with the suppression of immune mediators, such as INF- $\gamma$, and cytokines, such as IL-6, IL-4, and TNF- $\alpha$, which are also known to downregulate melanogenesis in melanocytes [18]. Alpha-melanocyte-stimulating hormone $(\alpha-\mathrm{MSH})$ increases the expression, de novo synthesis, and activation of tyrosinase [12,29,30]. $\alpha$-MSH stimulates the dendricity of melanocytes and protects them from superoxide radicals. The production of new melanin can repair the damage caused by ROS in apoptotic tissue [9,18,31,32]. ROS: reactive oxygen species; RNS: reactive nitrogen species; $A U V r$ : ultraviolet A radiation; BUVr: ultraviolet B radiation; $I N F-\gamma$ : interferon-gamma; $I L-18$ : interleukin $18 \mathrm{IL}-6$ : interleukin 6; $\alpha-M S H$ : alpha-melanocyte-stimulating hormone. 


\section{Conclusions}

Compared with healthy skin, HMOX1, SOD1, IL6 and IFN $\gamma$ were under-expressed in the skin lesions of patients with PA. However, $25 \%$ of biopsies with PA-related lesions showed over-expression of these four genes, and strong positive correlations between their expressions were also identified. As such, we propose the presence of molecular stages of PA, defined according to the over-expression (first stage) or under-expression (second stage) of HMOX1, SOD1, IL-6, and IFN $\gamma$ in abnormal tissue. These findings may have implications for the selection of treatments for PA-related lesions.

Supplementary Materials: The following are available online at http://www.mdpi.com/1010-660X/56/7/359/s1, Figure S1: Representation of the individual relative expression of genes, showing differences between skin with and without lesions.

Author Contributions: Conceptualization, M.L.M.-F. and A.E.C.-G.; methodology, M.L.M.-F., G.A.C.-P., I.G.-V., A.P.D.-A., and I.D.-E.; formal analysis, M.L.M.-F., G.A.C.-P., I.G.-V., and A.P.D.-A.; data curation, M.L.M.-F., G.A.C.-P., I.G.-V., and I.P.R.-S.; writing - original draft preparation, M.L.M.-F., G.A.C.-P., and J.R.-J.; writing-review and editing, M.L.M.-F., G.A.C.-P., I.G.-V., A.E.C.-G., I.P.R.-S., and I.D.-E.; supervision, A.E.C.-G. and V.F.-M.; project administration, M.L.M.-F.; funding acquisition, M.L.M.-F. and I.G.-V. All authors have read and agreed to the published version of the manuscript.

Funding: This research was funded in part by CONACyT: INFR-2014-01-225520, INFR-2015-01-254106, PDCPN-2015-01-63, SEP-CONACYT-CB-2015-258316, and SS/IMSS/ISSSTE-CONACYT-2016-01-273144.

Acknowledgments: The authors give thanks to all the study participants. The participation of Sergio Armando Flores Carranza in the search and classification of bibliography is also appreciated.

Conflicts of Interest: The authors declare no conflict of interest.

\section{References}

1. Hanson, S.G.; Nigro, J.F. Pediatric dermatology. Med. Clin. N. Am. 1998, 82, 1381-1403. [CrossRef]

2. Blessmann Weber, M.; Sponchiado de Ávila, L.; Albaneze, R.; Magalhães de Oliveira, O.; Sudhaus, B.; Ferreira Cestari, T. Pityriasis alba: A study of pathogenic factors. J. Eur. Acad. Dermatol. Venereol. 2002, 16, 463-468. [CrossRef]

3. World Health Organization. WHO Model Prescribing Information: Drugs Used in Skin Diseases. Available online: https://apps.who.int/medicinedocs/en/d/Jh2918e/ (accessed on 22 January 2020).

4. Jadotte, Y.T.; Janniger, C.K. Pityriasis alba revisited: Perspectives on an enigmatic disorder of childhood. Cutis 2011, 87, 66-72.

5. Castillo-Mori, Y.; Puescas Sánchez, P.; Díaz-Vélez, C.; Maldonado-Gómez, W.; Mendoza-Mego, B.; Alcóser-Arcila, A. Características clínico-epidemiológicas de pitiriasis alba en población de 6 a 16 años en colegios nacionales del distrito de Manuel A. Mesones Muro, Lambayeque, Perú. Acta Méd. Peru. 2011, 28, 73-78.

6. Guareschi, E.; Di Lernia, V. Infantile pityriasis alba and comorbid disorders. Pediatr. Health 2009, 3, 75-79. [CrossRef]

7. In, S.I.; Yi, S.W.; Kang, H.Y.; Lee, E.S.; Sohn, S.; Kim, Y.C. Clinical and histopathological characteristics of pytiriasis alba. Clin. Exp. Dermatl. 2008, 34, 591-597. [CrossRef]

8. Lin, J.Y.; Fisher, D.E. Melanocyte biology and skin pigmentation. Nature 2007, 445, 843-850. [CrossRef]

9. Tsatmali, M.; Ancans, J.; Thody, A.J. Melanocyte function and its control by melanocortin peptides. J. Histochem. Cytochem. 2002, 50, 125-133. [CrossRef]

10. Vaccaro, M.; Bagnato, G.; Cristani, M.; Borgia, F.; Spatari, G.; Tigano, V.; Saja, A.; Guarneri, F.; Cannavo, S.P.; Gangemi, S. Oxidation products are increased in patients affected by non-segmental generalized vitiligo. Arch. Dermatol. Res. 2017, 309, 485-490. [CrossRef]

11. D’Mello, S.A.N.; Finlay, G.; Baguley, B.C.; Askarian-Amiri, M.E. Signaling pathways in melanogenesis. Int. J. Mol. Sci. 2016, 17, 1144. [CrossRef]

12. Montaudié, H.; Bertolotto, C.; Ballotti, R.; Passeron, T. Fisiología del sistema pigmentario. Melanogénesis. EMC Dermatol. 2014, 48, 1-11. [CrossRef] 
13. Hubackova, S.; Kučerová, A.; Michlits, G.; Kyjacova, L.; Reinis, M.; Korolov, O.; Bartek, J.; Hodny, Z. IFN $\gamma$ induces oxidative stress, DNA damage and tumor cell senescence via TGF $\beta / S M A D$ signaling-dependent induction of Nox4 and suppression of ANT2. Oncogene 2015, 35, 1236-1249. [CrossRef] [PubMed]

14. Rodriguez-Arambula, A.; Torres-Alvarez, B.; Cortes-Garcia, D.; Fuentes-Ahumada, C.; Castanedo-Cazares, J.P. CD4, IL-17, and COX-2 are associated with subclinical inflammation in malar melasma. Am. J. Dermatopathol. 2015, 37, 761-766. [CrossRef] [PubMed]

15. Miazek, N.; Michalek, I.; Pawlowska-Kisiel, M.; Olszewska, M.; Rudnicka, L. Pityriasis Alba-Common disease, enigmatic entity: Up-to-date review of the literature. Pediatric Dermatol. 2015, 32, 786-791. [CrossRef]

16. Pityriasis Alba. Available online: https://dermnetnz.org/topics/pityriasis-alba/ (accessed on 30 March 2020).

17. Schmittgen, T.D.; Livak, K.J. Analyzing real-time PCR data by the comparative C(T) method. Nat. Protoc. 2008, 3, 1101-1108. [CrossRef]

18. Natarajan, V.T.; Ganju, P.; Ramkumar, A.; Grover, R.; Gokhale, R.S. Multifaceted pathways protect human skin from UV radiation. Nat. Chem. Biol. 2014, 10, 542-551. [CrossRef]

19. Cannavo, S.P.; Riso, G.; Di Salvo, E.; Casciaro, M.; Giuffrida, R.; Minciullo, P.L.; Guarneri, F.; Nettis, E.; Gangemi, S. Oxidative stress involvement in urticaria. J. Biol. Regul. Homeost. Agents 2020, 34, 675-678. [CrossRef]

20. Obrador, E.; Liu-Smith, F.; Dellinger, R.W.; Salvador, R.; Meyskens, F.L.; Estrela, J.M. Oxidative stress and antioxidants in the pathophysiology of malignant melanoma. Biol. Chem. 2019, 400, 589-612. [CrossRef]

21. Narayanan, D.L.; Saladi, R.N.; Fox, J.L. Ultraviolet radiation and skin cancer. Int. J. Dermatol. 2010, 49, 978-986. [CrossRef]

22. Troy, C.M.; D, D.; Prochiantz, A.; Greene, L.A.; Shelanskil, M.L. Downregulation of Cu/Zn superoxide dismutase leads to cell death $\mathrm{v} \&$ the nitric oxide-peroxynitrite pathway. J. Neurosci. 1996, 16, 253-261.

23. Kristal, L.; Klein, P.A. Atopíc dermatitis in infants and children: An update. Pediatr. Clin. N. Am. 2000, 47, 877-895. [CrossRef]

24. Castanet, J.; Ortonne, J.P. Pigmentary changes in aged and photoaged skin. Arch. Dermatol. 1997, 133, 1296-1299. [CrossRef] [PubMed]

25. Muñoz-Muñoz, J.L.; Garcia-Molina, F.; Varón, R.; Tudela, J.; Garcia-Canovas, F.; Rodriguez-Lopez, J.N. Generation of hydrogen peroxide in the melanin biosynthesis pathway. Biochim. Biophys. Acta 2009, 1795, 1017-1029. [CrossRef]

26. Podda, M.; Traber, M.G.; Weber, C.; Yan, L.-J.; Packer, L. UV-irradiation depletes antioxidants and causes oxidative damage in a model of human skin. Free Radic. Biol. Med. 1998, 24, 55-65. [CrossRef]

27. Vachtenheim, J.; Borovanský, J. "Transcription physiology" of pigment formation in melanocytes: Central role of MITF. Exp. Dermatol. 2010, 19, 617-627. [CrossRef] [PubMed]

28. Steinhoff, M.; Corvera, C.U.; Thoma, M.S.; Kong, W.; McAlpine, B.E.; Caughey, G.H.; Ansel, J.C.; Bunnett, N.W. Proteinase-activated receptor-2 in human skin: Tissue distribution and activation of keratinocytes by mast cell tryptase. Exp. Dermatol. 1999, 8, 282-294. [CrossRef]

29. Ramsden, C.A.; Riley, P.A. Tyrosinase: The four oxidation states of the active site and their relevance to enzymatic activation, oxidation and inactivation. Bioorg. Med. Chem. 2014, 22, 2388-2395. [CrossRef]

30. Reuter, S.; Gupta, S.C.; Chaturvedi, M.M.; Aggarwal, B.B. Oxidative stress, inflammation, and cancer: How are they linked? Free Radic. Biol. Med. 2010, 49, 1603-1616. [CrossRef]

31. Khansari, N.; Shakiba, Y.; Mahmoudi, M. Chronic inflammation and oxidative stress as a major cause of age-Related diseases and cancer. Recent Pat. Inflamm. Allergy Drug Discov. 2009, 3, 73-80. [CrossRef]

32. Pillai, S.; Oresajo, C.; Hayward, J. Ultraviolet radiation and skin aging: Roles of reactive oxygen species, inflammation and protease activation, and strategies for prevention of inflammation-induced matrix degradation-A review. Int. J. Cosmet. Sci. 2005, 27, 17-34. [CrossRef]

33. Moreno-Cruz, B.; Torres-Alvarez, B.; Hernandez-Blanco, D.; Castanedo-Cazares, J.P. Double-blind, placebo-controlled, randomized study comparing $0.0003 \%$ calcitriol with $0.1 \%$ tacrolimus ointments for the treatment of endemic pityriasis alba. Dermatol. Res. Pract. 2012, 2012, 303275. [CrossRef]

34. Costin, G.-E.; Hearing, V.J. Human skin pigmentation: Melanocytes modulate skin color in response to stress. FASEB J. 2007, 21, 976-994. [CrossRef] 
35. Kurutas, E.B. The importance of antioxidants which play the role in cellular response against oxidative/nitrosative stress: Current state. Nutr. J. 2016, 15, 71. [CrossRef]

36. Svobodova, A.; Vostalova, J. Solar radiation induced skin damage: Review of protective and preventive options. Int. J. Radiat. Biol. 2010, 86, 999-1030. [CrossRef]

(C) 2020 by the authors. Licensee MDPI, Basel, Switzerland. This article is an open access article distributed under the terms and conditions of the Creative Commons Attribution (CC BY) license (http://creativecommons.org/licenses/by/4.0/). 